\title{
INCORPORATION OF NEW TURBULENT CLOSURE SCHEMES IN THE PRINCETON OCEAN MODEL (POM)
}

\author{
José Francisco Almeida de Souza', José Luiz Lima de Azevedo², Leopoldo Rota de Oliveira², \\ Ivan Dias Soares ${ }^{3}$ and Maurício Magalhães Mata
}

\begin{abstract}
One of the most challenging issues in oceanography is the simulation of the mixing processes, which are responsible for diffusion of momentum, heat, salt, sediments, etc. In the modeling of flow, the hydrodynamic model simulates the properties of the mean flow while the turbulence model, coupled to the first, is responsible for simulating the mixing processes. In this article it is used the Princeton Ocean Model (POM), which includes the well known turbulent closure model $q^{2}-q^{2} L$ of Mellor \& Yamada (1982), level 2.5. To add flexibility to the modeling, the $k-\varepsilon$ and $k-\omega$ models, which belong to the same class of models, are incorporated into the POM and two test cases, one involving the deepening of the oceanic mixed layer and the other addressing the estuarine circulation, are carried out to allow the quality assessment of the models implementation in the computer code. The tests indicated that the model implementation was adequate. Comparing with the original model available in the Princeton Ocean Model, the results showed that the model $k-\varepsilon$ tends to overestimate the mixed layer, while the model $k-\omega$ underestimates it, within an acceptable range of tolerance. In terms of estuarine circulation, the $k-\varepsilon$ and $k-\omega$ models showed a greater capacity of mixing at the bottom of the estuarine mixing zone and also at the surface layer.
\end{abstract}

Keywords: turbulence models, mixing processes, two equation models, mixed layer, estuarine circulation.

RESUMO. Uma das questões mais desafiadoras em oceanografia é a simulação dos processos de mistura, responsáveis pela difusão de momentum, calor, sal, sedimentos etc. Na modelagem de escoamentos, o modelo hidrodinâmico simula as propriedades do escoamento médio, enquanto o modelo de turbulência, acoplado ao primeiro, é o responsável por simular os processos de mistura. Nesse artigo é utilizado o Princeton Ocean Model (POM), o qual traz acoplado 0 conhecido esquema de fechamento turbulento $q^{2}-q^{2} L$ de Mellor \& Yamada (1982), nível 2.5. Para adicionar flexibilidade à modelagem, os modelos $k-\varepsilon$ e $k-\omega$, da mesma categoria de modelos, são incorporados ao POM e dois casos-teste, um envolvendo 0 aprofundamento da camada de mistura oceânica e 0 outro a circulação estuarina, são realizados para permitir a avaliação da qualidade da implementação dos modelos no código computacional. Os testes indicaram que a implementação dos modelos foi adequada. Tendo como referência o modelo original do POM, os resultados mostraram que 0 modelo $k-\varepsilon$ tende a superestimar a camada de mistura, enquanto 0 $k-\omega$ a subestima, numa faixa aceitável de tolerância. Em termos de circulação estuarina, os modelos $k-\varepsilon$ e $k-\omega$ apresentaram uma maior capacidade de mistura tanto no fundo da zona de mistura estuarina como na camada superficial.

Palavras-chave: modelos de turbulência, processos de mistura, modelos a duas equações, camada de mistura, circulação estuarina.

\footnotetext{
1 Escola de Engenharia - EE, Universidade Federal do Rio Grande - FURG, Campus Carreiros, Av. Itália Km 8, Bairro Carreiros, $96201-900$ Rio Grande, RS, Brazil. Phone: +55(53) 3233-6876 - E-mail: zefran.souza@gmail.com

2Laboratório de Estudos dos Oceanos e Clima - LEOC, Instituto de Oceanografia - 10, Universidade Federal do Rio Grande - FURG, Campus Carreiros, Av. Itália Km 8, Bairro Carreiros, 96201-900 Rio Grande, RS, Brazil. Phone: +55(53) 3233-6851; +55(53) 3233-6854 - E-mails: joseazevedo@furg.br; leopoldorota@yahoo.com.br

${ }^{3}$ Associação ATLANTIS para o Desenvolvimento da Ciência - FURG, Rua Barão de Cotegipe, 653, 96200-290 Rio Grande, RS, Brazil. Phone: +55(53) 3233-5858 - E-mail: isoares@atlantis.org.br

${ }^{4}$ Laboratório de Estudos dos Oceanos e Clima - LEOC, Instituto de Oceanografia - 10, Universidade Federal do Rio Grande - FURG, Campus Carreiros, Av. Itália Km 8, Bairro Carreiros, 96201-900 Rio Grande, RS, Brazil. Phone: +55(53) 3233-6861 - E-mail: mauricio.mata@furg.br
} 


\section{INTRODUCTION}

The simulation of the mixing processes in coastal waters is one of the most challenging issues in oceanography (Thorpe, 2005). The river discharge, the tidal current effect and the barrier represented by the continental border produce in the continental shelf region temporal and spatial variations, in the velocity and density fields, which are much more intense than in the open ocean. The correct description of the vertical mixing processes in the hydrodynamic circulation models is the purpose of the called turbulence submodels (or simply, turbulence models), which are coupled to the first.

We can observe the concern of researchers to make available new turbulence closure alternatives in the circulation models, and thus provide the assessment of the most adequate model to the process under study. This is what has happened with TELEMAC, HYCOM, ROMS and other circulation models that provide many turbulence closure options to their users. With this same purpose, two new turbulence closure schemes will be incorporated into the Princeton Ocean Model (POM) in this work. As a turbulence submodel, the POM uses the Mellor \& Yamada (1982) closure scheme, level 2.5 (from now on called as MY82), which employs a transport equation for the turbulent kinetic energy $\left(k \equiv q^{2} / 2\right)$ and a second equation for the turbulent length macroscale represented by the product $q^{2} L$.

In literature, the two new turbulence closure models cited above are known as $k-\varepsilon$ and $k-\omega$. They also use two transport differential equations, one for the turbulent kinetic energy (TKE) and the other for the macroscale represented by $\varepsilon$ and $\omega$, respectively, and therefore being the same type of MY82 model.

Cushman-Roisin \& Beckers (2011) recognize that, in the geophysical flow scope, MY82 is the best known model, although other two equation models have been increasingly tested and used in this context (Burchard \& Petersen, 1999; Burchard \& Bolding, 2001; Burchard \& Deleersnijder, 2001; Umlauf et al., 2003; Umlauf \& Burchard, 2003; Warner et al., 2005; Peters \& Baumert, 2007; Burchard et al., 2008; llicak et al., 2008).

Literature shows that the $k-\varepsilon$ model has been widely employed and assessed in geophysical applications (e.g., Rodi, 1987; Rodi, 1993; Davies et al., 1995) and therefore its parameters are well known and accepted. In relation to the $k-$ $\omega$ model, two versions for industrial applications assigned to Wilcox (Wilcox, 1988 and Wilcox, 1998 apud Umlauf et al., 2003), that were never applied to geophysical flows on account of being inadequate to represent flows affected by stratification and by the Earth rotation, were adapted and assessed by these authors. According to Umlauf et al. (2003), only the model adapted from the 1988 version presented a comparable perfor- mance to the $q^{2}-q^{2} L$ (or $k-k L$ ) and $k-\varepsilon$ model of Rodi (1987) and in some relevant situations presented a better performance. This was the $k-\omega$ model version suggested by Umlauf et al. (2003) for geophysical applications. Warner et al. (2005) implemented these models to ROMS and carried out some test cases, including estuarine circulation, deepening of the mixed layer (ML) and suspended sediment transport, and concluded that all models presented a very similar performance. They highlight that the greatest variations among the models appear in the suspended sediment simulations and not in those that involve salinity concentrations, because the suspended sediment transport tends to amplify the minimal differences among the methods.

The turbulence models used in this work $\left(q^{2}-q^{2} L, k-\varepsilon\right.$ and $k-\omega$ ) are based on the turbulent viscosity concept and on the analogy with the kinetic theory, according to which the turbulent viscosity is proportional to a characteristic velocity scale of the movement fluctuations and to a characteristic length scale of this movement (e.g., Rodi, 1993). Among these models, the called two equation models stand out and are widely employed as turbulence submodels and, among the algebraic models, are considered the most complete models because they use two transport differential equations to determine the velocity and length scales (e.g., Warner et al., 2005), that are needed to determine the turbulent viscosity: one for the TKE and another for the turbulent length macroscale (TLM).

The $k-\varepsilon$ and $k-\omega$ model incorporation into the POM computer code adds more flexibility to the modeler, providing a range of alternatives for the turbulent process simulation. To understand the turbulence mechanisms in ocean and to study the way the mixing processes affect the mean flow, with different turbulence model alternatives for the simulation of these processes, is the strong motivation of this study.

The work is organized in the following way: initially, the governing equations used in the employed hydrodynamic model (POM) are presented. Then, the two equation turbulence closure model structure is discussed and the generic turbulence length scale $(\psi)$ is presented. After, the methodology employed to assess the implementation of new models in the POM computer code is treated and two test cases suggested in literature for such assessment are presented. Next, the numeric simulation results are presented and discussed and, finally, the conclusions.

\section{GOVERNING EQUATIONS}

In this section, the flow governing equations used in the POM, hydrodynamic model employed for the numeric simulations carried out in this work, will be presented. 
The POM belongs to a three-dimensional hydrodynamic model class and, for being in the public domain, it has been widely used by thousands of users in all continents for a large variety of different applications, since the hydrodynamic simulation of small scale lagoon environments up to the hydrodynamic of whole oceanic basins (e.g., Alves, 2006). A more detailed description of POM can be found in Mellor (2004). This model is constituted by the continuity, momentum conservation and scalar transport equations that, after Reynolds averaging application, result in the system:

$$
\begin{gathered}
\frac{\partial U_{i}}{\partial x_{i}}=0 \\
\frac{\partial U_{i}}{\partial t}+U_{j} \frac{\partial U_{i}}{\partial x_{j}}-f U_{j} \varepsilon_{i j 3} \\
=-\frac{1}{\rho_{0}} \frac{\partial P}{\partial x_{i}}-\frac{\rho g}{\rho_{0}} \delta_{i 3}+\frac{\partial}{\partial x_{j}}\left(v \frac{\partial U_{i}}{\partial x_{j}}-\overline{u_{i} u_{j}}\right) \\
\frac{\partial \Theta}{\partial t}+U_{i} \frac{\partial \Theta}{\partial x_{i}}=\frac{\partial}{\partial x_{i}}\left(\Gamma \frac{\partial \Theta}{\partial x_{i}}-\overline{u_{i} \theta}\right) \\
\frac{\partial S}{\partial t}+U_{i} \frac{\partial S}{\partial x_{i}}=\frac{\partial}{\partial x_{i}}\left(\Gamma \frac{\partial S}{\partial x_{i}}-\overline{u_{i} S}\right)
\end{gathered}
$$

where $U_{i}$ and $u_{i}$ are the average and fluctuating components of velocity, $f$ is the Coriolis parameter, $\varepsilon_{i j 3}$ is the alternating tensor, $P$ is the pressure, $\rho$ and $\rho_{o}$ are the total and reference densities, $-\overline{u_{i} u_{j}}$ is the Reynolds' tensor, $\Theta$ and $S$ are the average temperature and salinity, $\theta$ and $s$ are the temperature and salinity fluctuations and $\overline{u_{i} \theta}$ and $\overline{u_{i} s}$ represent the heat and salt fluxes, respectively. The system closure is obtained through the parameterization of Reynolds tensions and heat and salt fluxes, that take the forms:

$$
\begin{aligned}
& -\overline{u_{i} u_{j}}=K_{M}\left(\frac{\partial U_{i}}{\partial x_{j}}+\frac{\partial U_{j}}{\partial x_{j}}\right) \\
& -\overline{u_{i} \theta}=K_{H} \frac{\partial \Theta}{\partial x_{i}} \\
& -\overline{u_{i} s}=K_{H} \frac{\partial S}{\partial x_{i}}
\end{aligned}
$$

with

$$
K_{M}=q L S_{M}, \quad K_{H}=q L S_{H}
$$

In these expressions $K_{H}$ is the turbulent viscosity, $K_{H}$ is the heat and salt diffusivity and $S_{M}$ and $S_{H}$ are the called stability functions, which incorporate information about the shear and stratification effects over the second moments $\left(-\overline{u_{i} u_{j}},-\overline{u_{i} \theta}\right.$ and $-\overline{u_{i} s}$ ), that were lost in the algebrization process of Reynolds tensions to obtain the MY82 model (e.g., Mellor \& Yamada, 1982;
Galperin et al., 1988; Kantha \& Clayson, 1994; Burchard, 2002). The stability functions $S_{M}$ and $S_{H}$ employed in the POM are the functions proposed by Galperin et al. (1988), which depend on the buoyancy parameter $G_{H}$, and are obtained by

$$
S_{M}=\frac{\left.A_{1}\left[1-3 c_{1}-6 A_{1} / B_{1}\right]+S_{H}\left[18 A_{1}^{2}+9 A_{1} A_{2}\right) G_{H}\right]}{\left[1-9 A_{1} A_{2} G_{H}\right]}
$$

and

$$
S_{H}=\frac{A_{2}\left[1-6 A_{1} / B_{1}\right]}{\left[1-\left(3 A_{2} B_{2}+18 A_{1} A_{2}\right) G_{H}\right]}
$$

where $G_{H}$, buoyancy parameter, is defined by

$$
G_{H}=-\frac{L^{2}}{q^{2}} N^{2}
$$

and $N^{2}$, the Brunt-Väisälä frequence, by

$$
N^{2}=-\frac{g}{\rho_{o}} \frac{\partial \rho}{\partial z}
$$

In the expressions (7) and (8), $\left(A_{1}, A_{2}, B_{1}, B_{2}, C_{1}\right)=$ $(0.92 ; 0.74 ; 16.6 ; 10.1 ; 0.08)$ are the model parameters experimentally determined and $q$ is the square root of $q^{2}$, twice the turbulent kinetic energy. The $q^{2}$ and $L$ (length scale) variables represent characteristic turbulence quantities and need to be determined in order to close the equation set. The POM incorporates a turbulent closure scheme that uses two partial differential equations (PDEs), one for each quantity mentioned above. This type of model belongs to a turbulent closure model class called two equation mode/s, which is discussed in the next section.

\section{TWO-EQUATION TURBULENCE MODELS}

These models are based on the turbulent viscosity concept and on the Prandtl-Kolmogorov hypothesis according to which, and in analogy with the kinetic theory, the turbulent viscosity shall be proportional to a turbulence characteristic velocity $(\vartheta)$ and length $(L)$ scale, according to the expression

$$
K_{M} \propto \vartheta \cdot L .
$$

In this work the models that are addressed are the models that use two PDEs for the transport of two characteristic quantity of turbulence: an equation for the turbulent kinetic energy $\left(q^{2} / 2\right.$ in Mellor \& Yamada notation (1982) or $k$ in conventional notation) and a second equation for another characteristic quantity of turbulence that, in some way, is related to the length scale. The first equation, for the TKE, can be obtained by contraction of the Reynolds tension equation (see Deschamps, 2002 and Burchard, 
2002) and, after some unknown correlation modeling, takes the form

$$
\frac{\partial k}{\partial t}+U_{j} \frac{\partial k}{\partial x_{j}}-D=P_{S}+P_{B}-\varepsilon .
$$

In this equation, $D$ represents the TKE diffusive transport, $P_{S}$ and $P_{B}$ represent the TKE production by the mean flow shear and by the buoyancy, respectively, while $\varepsilon$ is the TKE dissipation rate, provided by

$$
\begin{aligned}
& D=\frac{\partial}{\partial z}\left(\frac{K_{M}}{\sigma_{k}} \frac{\partial k}{\partial z}\right) \\
& P_{S}=K_{M}\left[\left(\frac{\partial U}{\partial z}\right)^{2}+\left(\frac{\partial V}{\partial z}\right)^{2}\right] \\
& P_{B}=K_{H} \frac{g}{\rho_{o}} \frac{\partial \rho}{\partial z} \\
& \varepsilon=\frac{q^{3}}{B_{1} L}=\left(c_{\mu}^{0}\right) \frac{k^{3 / 2}}{L} .
\end{aligned}
$$

In expression (13), $\sigma_{k}$ is the Schmidt number while in expression (15) $\rho_{o}$ represents a reference density. The equation for the turbulence length scale does not necessarily need to have its own length scale " $L$ " as prognostic variable, because any $Z=k^{m} L^{n}$ type combination will be sufficient, as the turbulent kinetic energy " $k$ " is already known in the Equation (12) solution (e.g., Rodi, 1993). Most of the equations proposed until today do not use " $L$ " as dependent variable. The most important $k^{m} L^{n}$ combinations that have appeared over time are (e.g., Rodi, 1993; Deschamps, 2002): the dissipation rate, $\varepsilon\left(\propto k^{3 / 2} / L\right)$, the TKE product by the length scale $(=k L)$ and the characteristic turbulence frequency, $\omega\left(\propto k^{1 / 2} / L\right)$.

\section{The generic scale}

The two-equation models use Equation (12) for the TKE and a second equation for another representative quantity of the turbulent length scale, which can be any equation cited in the previous paragraph. This second equation is obtained in an heuristic approach and, in all models, it presents therefore a similar structure to Equation (12) structure. This structural similarity led Umlauf \& Burchard (2003) to propose a transport equation for a generic turbulent quantity $(\psi)$, from which it would be possible to reproduce any two-equation models that is used today and, eventually, clear the way for researchers to propose new models using other not explored turbulent quantities. This method is known as Generic Length Scale (GLS). Then generic model consists of Equation (12) for the TKE and the transport equation for the generic scale that, for having the same structure, can have the following form:

$$
\begin{gathered}
\frac{\partial \psi}{\partial t}+U_{j} \frac{\partial \psi}{\partial x_{j}}=F_{\psi}+\frac{\partial}{\partial z}\left(\frac{K_{M}}{\sigma_{\psi}} \frac{\partial \psi}{\partial z}\right) \\
+\frac{\psi}{k}\left(c_{\psi 1} P_{S}+c_{\psi 3} P_{B}-c_{\psi 2} \varepsilon F_{\text {Wall }}\right) .
\end{gathered}
$$

In expression (17), $\psi$ represents the parameter that is used to determine the turbulent macroscale, $F_{\psi}$ represents the horizontal diffusion term while the second term on the right side represents the $\psi$ vertical diffusion. The constants $c_{\psi 1}, c_{\psi 2}$ and $c_{\psi 3}$ are empiric parameters experimentally determined for each model and their values can be observed in Table 1. $F_{\text {wall }}$ is the wall proximity function. The generic parameter is expressed by (Umlauf \& Burchard, 2003):

$$
\psi=\left(c_{\mu}^{0}\right)^{p} k^{m} L^{n}
$$

where $\left(c_{\mu}^{0}\right)$ is a constant and $p, m$ and $n$ are coefficients that define the parameter that will represent the characteristic turbulence length scale. Theoretically, these coefficients may assume any real value. However, a specific value set leads to already known and explored characteristic turbulence quantities like the TKE dissipation rate, $\varepsilon$, or the turbulence frequency, $\omega$. A rearrangement in Equation (18) allows expressing the dissipation rate in the generic form like

$$
\varepsilon=\left(c_{\mu}^{0}\right)^{3+p / n} k^{3 / 2+m / n} \psi^{-1 / n}
$$

and the length scale in the form

$$
L=\left(c_{\mu}^{0}\right)^{-p / n} k^{-m / n} \psi^{1 / n} .
$$

The adequate choice of the $p, m$ and $n$ coefficients reproduces any model cited before and their values can be seen in Table 1.

It is worth pointing out that in Mellor \& Yamada (1982) notation, the TKE is represented by $q^{2} / 2$, where $q^{2}$ corresponds to twice the turbulent kinetic energy, instead of $k$, which is the conventional notation. As a consequence, this methodology does not directly reproduce the original model macroscale $q^{2} L$, but $k L$, in the conventional notation. The $S_{M}$ and $S_{H}$ stability functions, in Mellor \& Yamada notation, are represented in the conventional notation by the $c \mu$ and $c^{\prime} \mu$ symbols, respectively. The $c_{\mu}^{o}$ parameter represents the $c_{\mu}$ stability function value in experimental conditions with neutral stratification, where the value proposed by Kantha \& Clayson (1994) is 0.5544.

\section{Wall proximity function}

In the $q^{2}-q^{2} L$ model it is necessary to use a wall proximity function, as it uses a prognostic equation exactly for the characteristic length scale of the turbulence large scales, or of the most 
Table 1 - Parameters used in the models.

\begin{tabular}{|c|c|c|c|}
\hline Parameter & $\begin{array}{c}q^{2}-q^{2} L \\
\psi=q^{2} L\end{array}$ & $\begin{array}{c}k-\varepsilon \\
\psi=\left(c_{\mu}^{0}\right) k^{3 / 2} L^{-1}\end{array}$ & $\begin{array}{c}k-\omega \\
\psi=\left(c_{\mu}^{0}\right)^{-1} k^{1 / 2} L^{-1}\end{array}$ \\
\hline$p$ & 0.0 & 3.0 & -1.0 \\
$m$ & 1.0 & 1.5 & 0.5 \\
$n$ & 1.0 & -1.0 & -1.0 \\
$\sigma_{q}$ & 2.44 & 1.0 & 2.0 \\
$\sigma_{q}^{\psi}$ & 2.44 & 1.3 & 2.0 \\
$c_{1}$ & 0.9 & 1.44 & 0.555 \\
$c_{2}$ & 0.5 & 1.92 & 0.833 \\
$c_{3}$ & 0.9 & 1.0 & 1.0 \\
\hline
\end{tabular}

energetic vortices, which are related to the mean flow that, in turn, is the energy source that feeds the turbulence. In the proximities of a flow boundary surface, however, the vortex length scale is drastically reduced, by physical limitations, and tends to zero. Therefore, it is necessary to inform the model the boundary existence in the proximities of the analyzed point. This is carried out using the called wall proximity function, $F_{\text {Wall, }}$, in Equation (17). The purpose of these functions is to guarantee the decrease of the length scale near a boundary.

According to Umlauf \& Burchard (2003), Umlauf \& Burchard (2005) and Warner et al. (2005), the equations for $\varepsilon$ or $\omega$ do not need to inform the proximity of the boundaries. Mellor \& Yamada $(1974,1982)$ have already recognized the need of this function to guarantee the viscosity coefficient positivity. Warner et al. (2005) proved that any model with positive $n$ exponent in expression (18) (see Table 1) requires the use of the wall proximity function to guarantee the positivity of these coefficients. This is the case of the model $q^{2}-q^{2} L$. There are in literature different proposals to calculate this function. In the POM it takes a parabolic form provided by:

$$
F_{\text {wall }}=\left\{1+e_{2}\left[\frac{L}{\kappa}\left(\frac{1}{d_{S}}+\frac{1}{d_{B}}\right)\right]^{2}\right\}
$$

where $\kappa=0.41$ is the von Karman constant, $e_{2}=1.33$, $d_{S}$ and $d_{B}$ represent the distances to the free surface and to the bottom, respectively.

\section{Boundary conditions}

Inside the turbulent boundary layer, more specifically in the viscous and transition sublayers, where Reynolds number is smaller than 100 (see Souza et al., 2011), the molecular dissipation and diffusion assume values that are comparable to the turbulent analogues. Therefore, the models are in general incapable to model adequately and it is necessary to prescribe boundary con- ditions to allow the solution of the two equations in these regions (e.g., Deschamps, 2002; Fontoura Rodrigues, 2003). For the TKE, the boundary conditions (BC) for the surface and bottom, already implemented in the POM, are classic and correspond to

$$
\begin{aligned}
& k_{S}=\frac{\left(u_{*}^{S}\right)^{2}}{\left(c_{\mu}^{0}\right)^{2}} \\
& k_{B}=\frac{\left(u_{*}^{B}\right)^{2}}{\left(c_{\mu}^{0}\right)^{2}}
\end{aligned}
$$

which are the application result of the logarithmic law of the wall in this constant tension layer (e.g., Warner et al., 2005). In (22) and (23), $u_{*}$ is the friction velocity and the " $S$ " and " $B$ " indices indicate that the variable is expressed in the surface and in the bottom, respectively. As $B_{1}=2^{3 / 2} /\left(c_{\mu}^{0}\right)^{3}$, we can express this BC in Mellor \& Yamada (1982) notation in the form (see Mellor, 2004; Mellor \& Blumberg, 2004; Warner et al., 2005),

$$
q^{2}=B_{1}^{2 / 3} \mu_{*}^{2} .
$$

The turbulent kinetic energy equation (12), that exists in the computer code, will not have any alteration and, therefore, it is not necessary to define any additional $B C$ for it besides the relation (24).

For the $\psi$ generic parameter of equation (17) it is necessary to define boundary conditions to the bottom and surface, once the computer code modifications basically operate in the equation for this quantity.

\section{a) Boundary conditions for the length scale}

When $p=0, m=1.0$ and $n=1.0$ in expression (18), the quantity represented by the $\psi$ parameter is $k L$ or $q^{2} L$ in Mellor \& Yamada (1982) notation and, in this case, the boundary conditions have already been implemented in the POM. For the surface, $q^{2} L_{(\text {sur })}=0$, and for the bottom, $q^{2} L_{(\text {bottom })}=0$. 
Both segments suggest that the variable tends to zero when the $z$ distance to the boundary tends to zero (see Mellor, 2004).

For other quantities, like $\varepsilon$ and $\omega$, it will be necessary to define new boundary conditions due their different physical nature. It is worth highlighting that the boundary conditions for the $q^{2} L$ equation, already implemented in the POM, are like Dirichlet conditions, that is, they define the variable value in the boundary. Then, the conditions to be implemented to the $\psi$ variable will also be like Dirichlet conditions. The $\psi$ value in the boundary can be determined using the expression (18). Replacing the TKE, derived from (22) and (23), in this expression (18) and specifying $L=\kappa z$ (length scale proportional to the distance to the wall in the viscous sublayer), generic expressions very useful for the $B C$ application are obtained (e.g., Warner et al., 2005). The boundary conditions obtained by this way take the forms:

$$
\begin{aligned}
& \psi_{(\text {sur })}=\left(c_{\mu}^{0}\right)^{p-2 m}\left(u_{*}^{s}\right)^{2 m} \kappa^{n} z_{\text {sur }}^{n} \\
& \psi_{(\text {Bottom })}=\left(c_{\mu}^{0}\right)^{p-2 m}\left(u_{*}^{B}\right)^{2 m} \kappa^{n} z_{B}^{n} .
\end{aligned}
$$

\section{b) Boundary conditions for the $\varepsilon$ parameter}

For the $k-\varepsilon$ model, the application of the (25) and (26) boundary conditions together with Table 2 , which provides $p=3.0$, $m=3 / 2$ and $n=-1.0$, leads to,

$$
\begin{aligned}
\psi_{(\text {sur })}= & \varepsilon_{(\text {sur })}=\left(u_{*}^{S}\right)^{3}\left(\kappa z_{S}\right)^{-1}=\frac{\left|u_{*}^{S}\right|^{3}}{\kappa z_{S}} \\
& \psi_{(\text {Bottom })}=\varepsilon_{(\text {Bottom })} \\
= & \left(u_{*}^{B}\right)^{3}\left(\kappa z_{B}\right)^{-1}=\frac{\left|u_{*}^{B}\right|^{3}}{\kappa z_{B}} .
\end{aligned}
$$

\section{c) Boundary conditions for the $\omega$ parameter}

For the $k-\omega$ model, the application of the (25) and (26) boundary conditions together with Table 2 , which provides $p=-1.0, m=1 / 2$ and $n=-1.0$, leads to,

$$
\begin{aligned}
& \psi_{(\text {sur })}=\omega_{(\text {sur })}=\frac{\left(u_{*}^{S}\right)}{\left(c_{\mu}^{0}\right)^{2}\left(\kappa z_{S}\right)} \\
& \psi_{(\text {Bottom })}=\omega_{(\text {Bottom })}=\frac{\left(u_{*}^{B}\right)}{\left(c_{\mu}^{0}\right)^{2}\left(\kappa z_{B}\right)}
\end{aligned}
$$

Therefore, the boundary conditions are defined for all turbulence models used in this work.

\section{METHODOLOGY}

The methodology employed in this work consists of two steps: (i) the implementation of the new turbulent model equations in the POM and (ii) this implementation assessment, that will allow the use of the new models in real situations.

The GLS method proposed by Umlauf \& Burchard (2003), described in the previous sections, was used to implement the $k-\varepsilon$ and $k-\omega$ models in the POM, which has already incorporated the $q^{2}-q^{2} L$ model. With this implementation, the equation for the TKE remains exactly the same of the original model (MY82). However, the original transport equation for the turbulent length scale was adapted to represent the $\psi$ generic scale defined by the equation (17).

It is necessary to assess the implementations carried out to correct eventual problems to use the new models incorporated into the POM computer code in oceanographic applications (Burchard \& Deleersnijder, 2001). These problems may comprise common codification errors, poor boundary condition implementation and realisability constraints of each model, among others. For this purpose, some test cases are recommended in literature to check the performance of a turbulence subroutine or to compare the different turbulence model results (e.g., Burchard \& Petersen, 1999; Burchard \& Deleersnijder, 2001; Umlauf et al., 2003; Umlauf \& Burchard, 2003; Umlauf et al., 2005; Warner et al., 2005).

Thus, two test cases were selected for this purpose. The first assess the deepening of the oceanic mixed layer in a channel, based on the classic Kato \& Phillips (1969) experiment, with the Burchard \& Deleersnijder (2001) and Burchard \& Bolding (2001) adaptations for the oceanic scale. The second test case tries to simulate the estuarine circulation in a long channel induced by river discharge in one end (head) and sinusoidal tide in the other (mouth), in the form proposed by Warner et al. (2005). Next, these test cases will be better described.

\section{a) Deepening of the oceanic mixed layer}

The correct prediction of the deepening of the mixed layer (DML), due the wind tension acting on the surface, is one of the most critical requirement to be fulfilled by an oceanic turbulence model (e.g., Umlauf \& Burchard, 2003). As the DML measurements in the real ocean are in general contaminated by the effect of the horizontal divergence of movement and by the internal wave action, the turbulence model checking, in general, is carried out comparing them to laboratory experiments (e.g., Kantha \& Clayson, 1994; Umlauf et al., 2003).

The classic Kato \& Phillips (1969) experiment is a standard reference in the modeling community (e.g., Burchard \& Petersen, 1999; Burchard \& Deleersnijder, 2001; Umlauf et al., 2003; Umlauf \& Burchard, 2003; Warner et al., 2005). In this experiment, water in a channel reproduced in laboratory scale, linearly 
stratified in the beginning, undergoes a constant superficial tension. This tension produces shear on the superficial layers. Shear generates turbulence, promotes mixing and homogenization on the upper part of the water column, destroying then the initial stratification. As time goes by, the mixed layer induced by this tension penetrates in the fluid just below, stably stratified, and the thermocline depth (or pycnocline) increases. Price, in 1979 (cited by Burchard \& Petersen, 1999), suggested an empiric solution for the mixed layer depth evolution with time, $D(t)$, from the Kato \& Phillips (1969) laboratory experiment results, in the form

$$
D(t)=1.05 \frac{u_{*}}{\sqrt{N_{0}}} t^{1 / 2},
$$

where $N_{o}$ is the initial Brunt-Väisälä frequency value and $u_{*}=\sqrt{\tau_{s} / \rho_{o}}$ is the superficial friction velocity. Burchard \& Deleersnijder (2001) and Burchard \& Bolding (2001) used the Similarity Theory to adapt this experiment results to the oceanic dimensions, and obtained then the $u_{*}=0.01 \mathrm{~ms}^{-1}$ and $N_{o}=0.01 \mathrm{~s}^{-1}$ values.

In a similar way to the experiment presented in literature, the numeric experiment carried out in this work will have 30 hour duration, and the corresponding empiric solution, using Equation (31), results in $D(30 \mathrm{~h})=34.5 \mathrm{~m}$. The experiment will be carried out in a channel with 6,650 $\mathrm{m}$ for length, $440 \mathrm{~m}$ for width and $50 \mathrm{~m}$ for constant depth. Other geometric and numeric characteristics are presented in Table 2. Initially the basin will have water at rest and, over its surface, a wind with $8.6 \mathrm{~ms}^{-1}$ velocity will blow, producing $\tau_{S}$ tension with $0.10 \mathrm{Nm}^{-2}$ for intensity, which will be uniformly applied to all domain superficial points. The main experiment parameters are presented in Table 2.

Table 2 - Geometric and numeric parameters of test case n. 1.

\begin{tabular}{|l|l|}
\hline \multicolumn{1}{|c|}{ Experiment parameters } & \multicolumn{1}{|c|}{ Values } \\
\hline Length, width, depth & $6650 \mathrm{~m}, 440 \mathrm{~m}, 50 \mathrm{~m}$ \\
Grid element number (Im, Jm, Kb) & $19,11,100$ \\
Bottom rugosity & $0.005 \mathrm{~m}$ \\
Internal mode time step & $12 \mathrm{~s}$ \\
External mode time step & $0.4 \mathrm{~s}$ \\
Temperature (surface / bottom) & $10^{\circ} \mathrm{C} / 8^{\circ} \mathrm{C}$ \\
\hline
\end{tabular}

The channel extends in the east-west direction. In the open boundaries (east and west) cyclic numeric boundary conditions (Periodic Open Boundaries) will be employed. In the closed boundaries (north and south), the boundary conditions will be automatically applied using "masks" that allow a velocity tangential to the boundary and nullify the normal velocities (e.g., Mellor, 2004. The salinity will be constant and uniform during the simulation, with 30 psu (practical salinity unit) in all grid points. No heat nor mass flux will be allowed through the bottom or the free surface. The constant salinity turns the density a function of temperature only and, therefore, the initial stratification with $N_{o}=0.01 \mathrm{~s}^{-1}$ will be provided through an initial temperature profile that linearly varies from $10^{\circ} \mathrm{C}$ on the surface to $8^{\circ} \mathrm{C}$ on the bottom.

Literature cites some criteria that may be used to determine the ML depth. One of these criteria uses the TKE gradient for this purpose. A peak in this gradient value identifies the lower limit of this layer. Burchard \& Petersen (1999), for example, used the density gradient peak as an indicator of the mixed layer base.

The surface mixed layer is distinguished by the TKE highest level in relation to the fluid below the pycnocline, still stratified and at rest. Due to its simplicity, this was the criterium employed in this work to identify this layer depth. According to this criterion, the purpose is to identify in the water column (in this case, the one that corresponds to the numeric grid central point) the greatest depth point with TKE still greater than $1.0 \mathrm{e}-5 \mathrm{~m}^{2} \mathrm{~s}^{-2}$. Therefore, all water column points with $k>1.0 \mathrm{e}-5 \mathrm{~m}^{2} \mathrm{~s}^{-2}$ belong to the surface ML, while points with $k<1.0 \mathrm{e}-5 \mathrm{~m}^{2} \mathrm{~s}^{-2}$ will belong to the stratified and quiescent lower layer. It is worth pointing out that the TKE in the mixed layer assumes values about $10^{-2} \mathrm{~m}^{2} \mathrm{~s}^{-2}$ (this can be confirmed in Figure 5 just below) while in the bottom quiescent layer it assumes background values about $5.0 \mathrm{e}-6 \mathrm{~m}^{2} \mathrm{~s}^{-2}$. Thus, the choice of $k$ values much lower than $10^{-2} \mathrm{~m}^{2} \mathrm{~s}^{-2}$ and above the background value will not surely affect the LM depth.

\section{b) Estuarine circulation}

The second test case, suggested in Warner et al. (2005), provides a way to assess the model ability to represent the typical mixing processes of estuarine channels. It encompasses the solution time-dependent of the circulation and mixing time in an initially horizontally stratified estuary. The model domain is constituted by a long $(100 \mathrm{~km})$ and narrow $(550 \mathrm{~m})$ channel with depth linearly varying from $5 \mathrm{~m}$ in the head (river) to $10 \mathrm{~m}$ in the mouth (ocean). Other geometric and numeric characteristics can be observed in Table 3. This idealized estuary will be employed in this work to simulate the movement components of a channel that receives an upstream (head) fluvial input that is subject to a semidiurnal tidal wave, that penetrates downstream (mouth). Some characteristics and parameters that will be employed in this numeric experiment are presented in Table 3.

The sole forcings used in this experiment are the barotropic velocities applied as the boundary condition form through the fluvial discharge and the semidiurnal tide current, with literature 
Table 3 - Geometric and numeric parameters of test case n. 2.

\begin{tabular}{|l|l|}
\hline \multicolumn{1}{|c|}{ Experiment parameters } & \multicolumn{1}{|c|}{ Values } \\
\hline Length, width, depth & $100,000 \mathrm{~m}, 550 \mathrm{~m}, 5$ to $10 \mathrm{~m}$ (variable) \\
Grid element number (Im, Jm, Kb) & $100,11,20$ \\
Grid elements $(\Delta x, \Delta y, \Delta z)$ & $1000 \mathrm{~m}, 50 \mathrm{~m}, 0.25$ to $0.50 \mathrm{~m}$ \\
Bottom rugosity & $0.005 \mathrm{~m}$ \\
Internal mode time step & $60 \mathrm{~s}$ \\
External mode time step & $2 \mathrm{~s}$ \\
\hline
\end{tabular}

suggested values. The fluvial discharge will be applied imposing a $\bar{U}_{\text {river }}=0.08 \mathrm{~ms}^{-1}$ velocity in the head section, according to

$$
\begin{aligned}
& q_{\text {river }}=\bar{U}_{\text {river }} \bar{H}_{\text {hea }}=0.08 \bar{H}_{\text {hea }} \\
& \bar{u}_{\text {hea }}=\frac{0.08 \bar{H}_{\text {hea }}}{\left(\bar{H}_{\text {hea }}+\eta_{\text {hea }}\right)} .
\end{aligned}
$$

In these expressions the subindex "hea" indicates that the variable is determined in the head section. $\bar{H}$ and $\eta$ are the channel depth and the free surface displacement, respectively, $q_{\text {river }}$ is the river flow by channel width unit (fluvial input) and $\bar{u}$ is the promediated velocity in the vertical.

The tidal current will be applied at the channel maritime end (i.e., downstream), through the $\bar{U}_{\text {tide }}=0.40 \mathrm{~ms}^{-1}$ velocity, in the form of a sinusoidal function, with the following adaptation:

$$
\begin{aligned}
& q_{\text {tide }}=\bar{U}_{\text {tide }} \bar{H}_{\text {mou }} \sin (\omega t)=0.40 \bar{H}_{\text {mou }} \sin (\omega t) \\
& \bar{u}_{\text {hea }}=\frac{\left(q_{\text {river }}-q_{\text {tide }}\right)}{\left(\bar{u}_{\text {hea }}+\eta_{\text {mou }}\right)} .
\end{aligned}
$$

In these expressions the subindex "mou" indicates that the variable is determined in the mouth section, $q_{\text {tide }}$ is the flow imposed by the tide by channel width unit, $t$ is the modeling time, $\omega=2 \pi / T$ is the angular frequency and $T$ is the tidal period.

The relative importance between the tide and fluvial discharge forcings is determined by the dimensionless called flux ratio $(R F)$, which is estimated by the ratio between the fluvial water volume $(R)$ that enters in the estuary during one tidal period, where $R=q_{\text {river }} T$, and the tidal prism $(P)$, defined by the seawater volume that enters in the estuary during the flood tide, that is, $P=h_{o} A_{S}$, where $h_{o}$ is the tide height and $A_{S}$ is the estuary surface area. We can deduce from the flux ratio definition that when $R F \geq 1$, the estuary is dominated by the fluvial discharge and, thus, it is highly stratified. On the contrary, when $R F<0.1$, the estuary is dominated by the tide and, thus, it is very mixed. For intermediate values, the estuary is considered partially mixed or partially stratified (e.g., Miranda et al., 2002). The adopted velocities lead to the $R F \approx 0.40$ value of the flux ratio indicating a estuary partially stratified (e.g., Souza, 2011). Table 4 presents a summary of these boundary conditions.

Temperature is constant and equal to $10^{\circ} \mathrm{C}$ in all domain while the initial salinity field is uniform in each channel end and it is applied in the following way: Up to a $20 \mathrm{~km}$ distance from the head, the salinity is null, while in the $30 \mathrm{~km}$ at the final segment of the estuary the salinity is $30 \mathrm{psu}$. Between these two regions the salinity linearly varies, as it is indicated in Figure 1.

\section{RESULTS AND DISCUSSION}

In the first experiment the simulation is carried out for 30 hours, corresponding to Kato \& Phillips (1969) experiment adapted to the oceanic scale by Burchard \& Deleersnijder (2001) and Burchard \& Bolding (2001). The constant wind tension drag the superficial layers generating a velocity gradient that transfers energy to the movement turbulent component. The turbulent agitation generated this way homogenizes the upper part of the water column and creates a superficial mixed layer with a uniform and greater (smaller) temperature (density) than that of the lower layers. On the base of this mixed layer a strong temperature (density) gradient appears and this gradient characterizes the thermocline (pycnocline), which separates the surface layer from the bottom layer, still stratified.

Figure 2 presents the result obtained for the deepening of the surface mixed layer for the $q^{2}-q^{2} L, k-\varepsilon$ and $k-\omega$ models. The solid line represents the empiric solution, as it was described in the last section.

We can observe that the three models simulated the mixed layer deepening with good concordance with the empiric solution. Still in Figure 2 we can observe that the $q^{2}-q^{2} L$ model presented a light oscillation regarding the empiric solution, and this may be related to the use of the wall proximity function that only this model uses. The $k-\varepsilon$ and $k-\omega$ models presented smoother solutions. In relation to the $k-\varepsilon$ model, positive discrepancies were observed all time, indicating that this model can produce a more intense mixing than the other models, over- 
Table 4 - Summary of the boundary conditions for test case n. 2.

\begin{tabular}{|l|l|}
\hline \multicolumn{1}{|c|}{ River end (upstream) } & \multicolumn{1}{c|}{ Oceanic end (downstream) } \\
\hline $\bar{H}^{\text {river }}=5 \mathrm{~m}$ & $\bar{H}^{\text {tide }}=10 \mathrm{~m}$ \\
\hline $\bar{U}^{\text {river }}=0.08 \mathrm{~ms}^{-1}$ & $\bar{U}^{\text {tide }}=0.4 \mathrm{~ms}^{-1}$ \\
\hline$q^{\text {river }}=\bar{U}^{\text {river }} \bar{H}^{\text {hea }} \mathrm{m}^{2} \mathrm{~s}^{-1}$ & $Q^{\text {tide }}=\bar{U}^{\text {tide }} \bar{H}^{\text {hea }} \sin (2 \pi t / T) \mathrm{m}^{2} \mathrm{~s}^{-1}$ \\
\hline $\bar{u}^{\text {hea }}=q^{\text {river }} /\left(\bar{H}^{\text {hea }}+\eta^{\text {hea }}\right) \mathrm{ms}^{-1}$ & $\bar{u}^{\text {hea }}=\left(q^{\text {river }}-q^{\text {tide }}\right) /\left(\bar{H}^{\text {hea }}+\eta^{\text {hea }}\right) \mathrm{ms}^{-1}$ \\
\hline
\end{tabular}

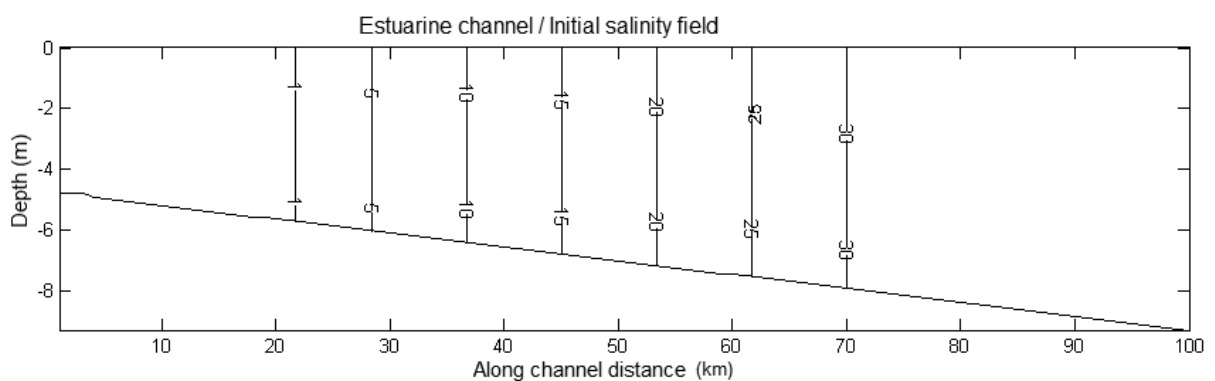

Figure 1 - Initial salinity (psu) distribution for test case n. 2.

estimating then the deepening of the mixed layer in relation to the empiric solution. On the contrary, the $k-\omega$ model underestimated the ML deepening, indicating a smaller mixing capacity.

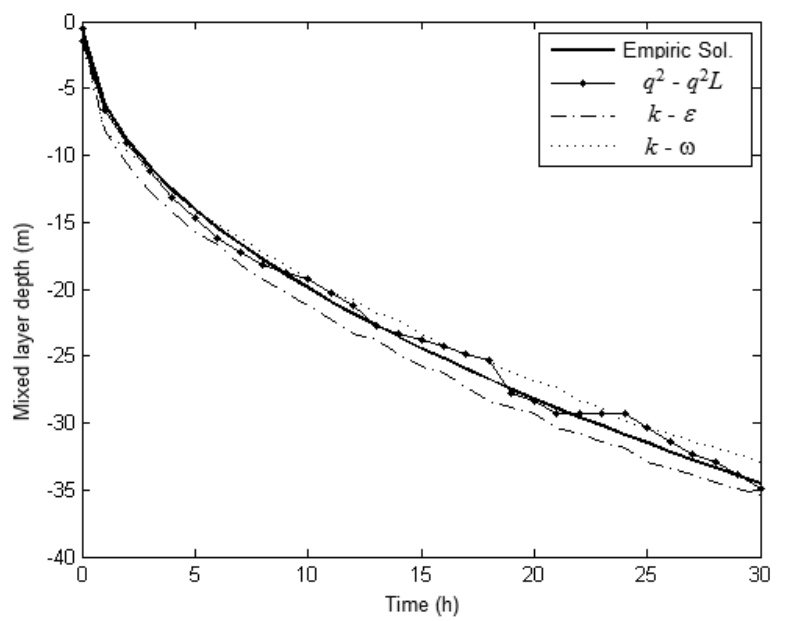

Figure 2 - Mixed layer evolution in function of time with the $q^{2}-$ $q^{2} L(M Y 82), k-\varepsilon(G L S)$ and $k-\omega(G L S)$ models.

At the end of the experiment, after 30 hours of constant wind, we can note that the $k-\omega$ model presented the greatest discrepancy $(-1.61 \mathrm{~m}$ or $-4.7 \%)$ in relation to the empiric solution, the $q^{2}-q^{2} L$ model produced the smallest one $(0.41 \mathrm{~m}$ or $+1.2 \%)$ and the $k-\varepsilon$ model was situated between these limits $(-0.92 \mathrm{~m}$ or $+2.7 \%)$.

Burchard \& Deleersnijder (2001) performed the same experiment and also observed with the $q^{2}-q^{2} L$ model the oscillations cited above on the base of the mixed layer. They com- mented that the increase of the $c_{3}$ coefficient, corresponding to the production term of the TKE by the buoyancy, from 0.9 to 5.0 [see Equation (17) and Table 1] eliminated these oscillations. The same procedure was carried out in this work but, besides not eliminating the oscillations, it substantially reduced the deepening of the mixed layer and, thus, the referred coefficient was maintained in 0.9. This result was already expected considering that, in stratified flows, the production term by the buoyancy acts as an energy sink, damping therefore the turbulence.

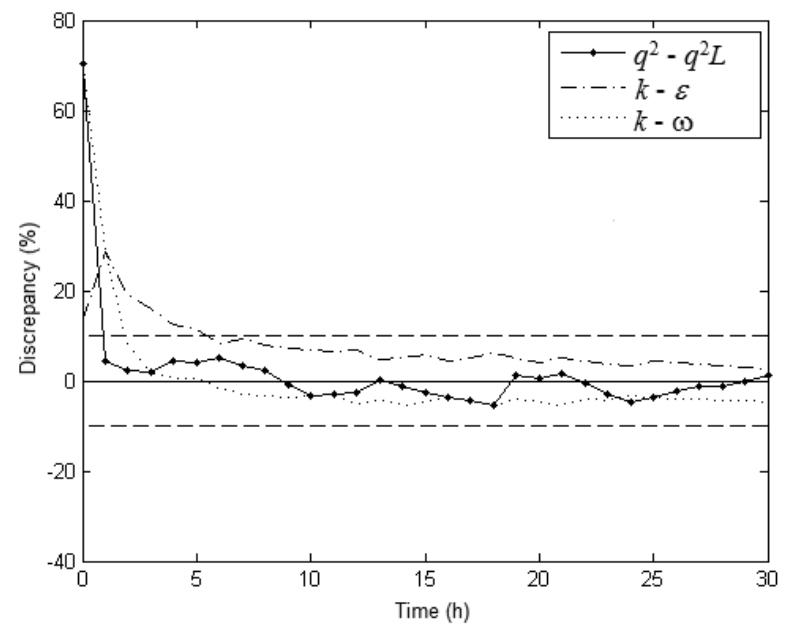

Figure 3 - Percentage discrepancy between the numeric solution obtained with each model and the empiric solution. The dashed lines delimit a range where this discrepancy is about $\pm 10 \%$.

In Figure 3 the percentage discrepancy between the numeric solution obtained with each model and the empiric solution for 

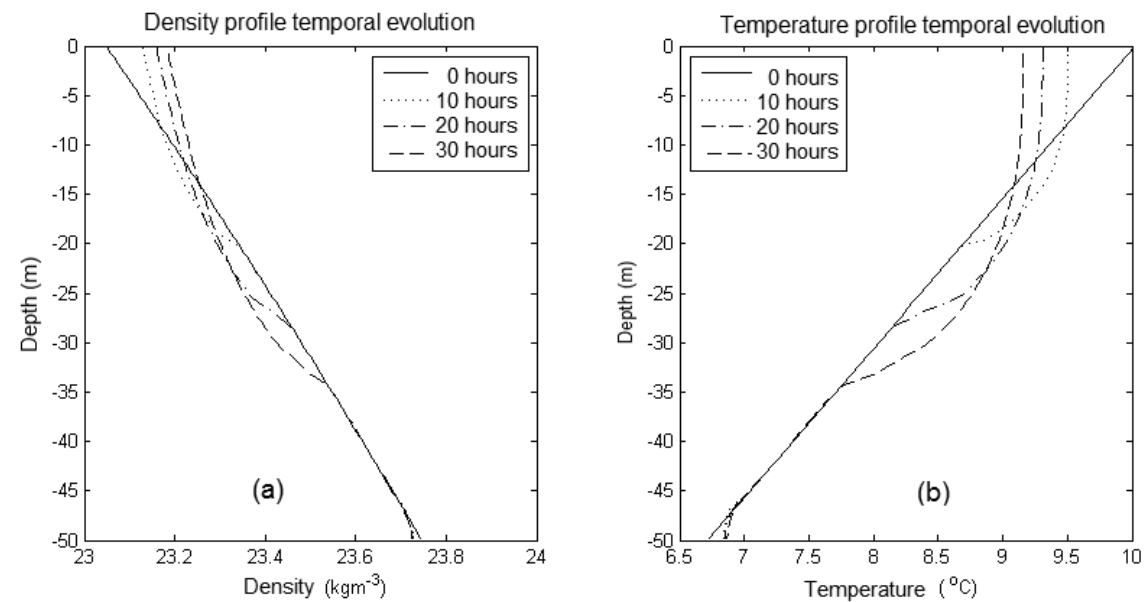

Figure 4 - Temporal evolution of the (a) density and (b) temperature profiles from the initial linear profiles.

each instant is presented. In this figure, the dashed lines delimit a range where this discrepancy is about $\pm 10 \%$. We can clearly note that, after 10 hours, all models presented a reasonably uniform behaviour, including the $q^{2}-q^{2} L$ model that, despite the oscillations, was within these limits.

The temperature and density profile temporal evolution (remember density is a function of temperature only as salinity was constant and uniform during the experiment) was also followed in the same grid central point. In Figure 4 the temporal evolution of these two profiles obtained with model $k-\varepsilon$ is presented. For the other models the profile evolution is similar and, therefore, it is not presented. On the left (right) side of the figure each line represents the density (temperature) profile that was taken each hour from the beginning of the experiment.

An analysis of Figure 4 shows that the mixed layer is formed with increasing time, from the initial linear profile, with the temperature decrease on the surface and increase on the base of this layer, as it is theoretically forecasted, tending to the verticalization of the lines within the ML, as a result of the density (or temperature) homogenization. This highlights that the buoyancy forces, damping the turbulence in this scenario, although being present in this layer, are not significant when they are compared to the shear effect caused by the superficial wind tension. Therefore we can conclude that the shear process is more relevant than the buoyancy process. In both Figure 4 profiles we can observe that the superficial ML deepens up to nearly $35 \mathrm{~m}$, in concordance with Figure 2 and with the empiric result $(34.5 \mathrm{~m})$.

Some turbulent parameters that are more relevant for the performance comparison of the models are presented in Figure 5 for the final instant of the experiment ( 30 hours). We can note that the three profiles, corresponding to the three analyzed models, have curves with similar formats for each parameter, demonstrating that the new model implementation was adequate.

We can observe that the viscosity coefficient, for all models, presented values about $10^{-2} \mathrm{~m}^{2} \mathrm{~s}^{-1}$ in the surface mixed layer. Therefore, much greater values than the background value (5.0e-6 $\left.\mathrm{m}^{2} \mathrm{~s}^{-1}\right)$ as it was expected, indicating the presence of a relatively intense mixing in this layer. We can also observe that these coefficients assume the greatest values near the shear source (surface) and they quickly decrease up to nearly $5 \mathrm{~m}$. From this depth, they decrease more slowly up to the base of the mixed layer where the agitation ceases. In the quiescent and stratified layer, below the pycnocline, these coefficients assume the background value.

In Figure 5 we can note that the TKE profiles present some variation from model to model but the energetic levels are comparable in all, also indicating that the implementations were successful. Most of the energy produced by the three models is restricted to the medium depth of the ML and it smoothly decreases towards the base of this layer. In depths below $35 \mathrm{~m}$, approximately, the TKE production ceases for all models in conformity with Figure 2.

The viscosity coefficients shown in Figure 5 indicate that the models produce different mixing intensity along the ML. We can also observe that near the surface the mixing production is greater, specially by the $k-\varepsilon$ model, but it gradually decreases towards the bottom and it completely ceases below $35.4 \mathrm{~m}$. The figure also shows that, in each depth, the different models produce different TKE quantities. Up to the $25 \mathrm{~m}$ depth, for example, the $q^{2}-q^{2} L$ model produces more TKE than the $k-\varepsilon$ model, while in depths greater than $25 \mathrm{~m}$ this situation is inverted and the $k-\varepsilon$ model then transfers more energy from the medium flow 


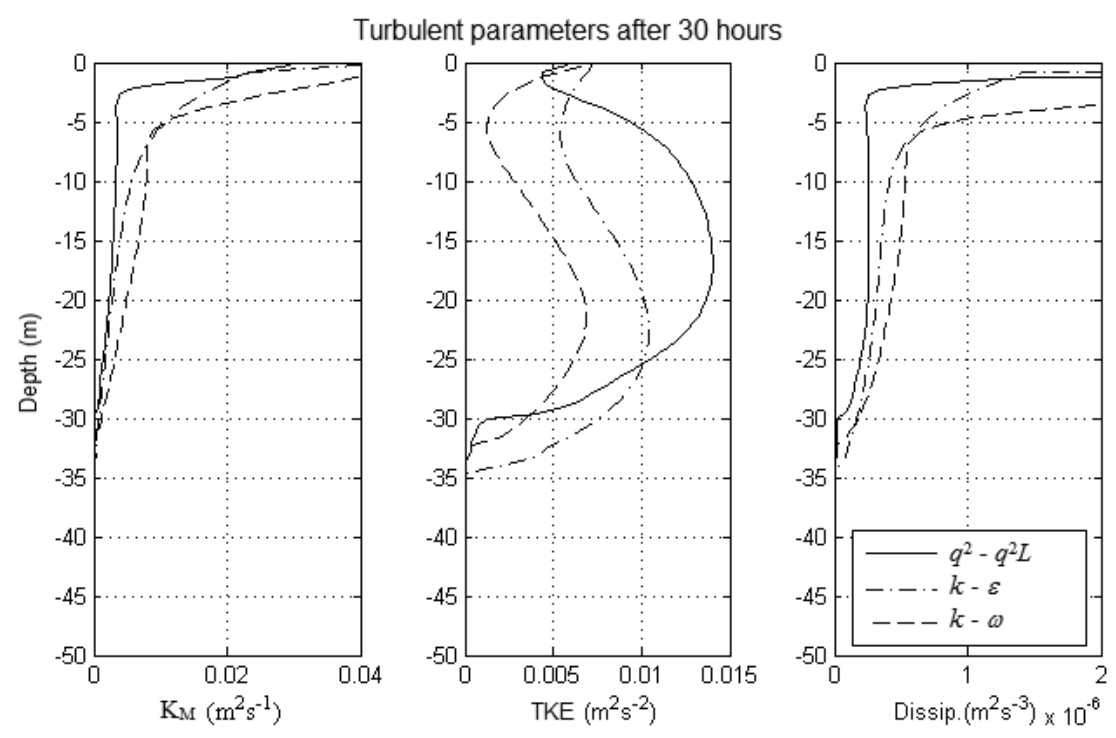

Figure 5 - Turbulent parameters after 30 hours. From left to right: turbulent viscosity $\left(K_{M}\right)$, turbulent kinetic energy (TKE) and TKE dissipation rate.

to the turbulent one. Apparently, the best correlation among the depths where the TKE reaches its maximum value for each model occurs with the length scale of the most energetic vortices, as the two right panels in Figure 5 show. In this figure we note that the depths where the TKE and the TLM reach their maximum values are approximately coincident.

The supremacy of the shear destabilizing effect over the stratification stabilizing effect occurs up to the pycnocline (thermocline) base situated at the $32.9 \mathrm{~m}, 34.9 \mathrm{~m}$ and $35.4 \mathrm{~m}$ for the $k-\omega, q^{2}-q^{2} L$ and $k-\varepsilon$ models, respectively, in conformity with Figures 2 and 3.

In the second experiment, the evolution and final distribution of the salinity field in the estuary are controlled by the mixing process. According to Warner et al. (2005), the results are very sensitive to the $\bar{U}_{\text {river }}$ and $\bar{U}_{\text {tide }}$ value choice but, once these values are fixed, consistent differences among the turbulence models can be observed. Radioactive boundary conditions were used for all variables. In this work we are going to define the saline wedge extent as the distance, above estuary, reached by the $1 \mathrm{psu}$ isohaline. The mixing processes of interest occur in this region, which will be referred from now on as mixing zone (MZ), according to Miranda et al. (2002).

The $q^{2}-q^{2} L, k-\varepsilon$ and $k-\omega$ turbulence models were applied and the salinity field at the end of the high tide on the twentieth day (after 40 tidal cycles) is shown in Figure 6. As we can observe, the result led to a partially mixed estuary with a MZ that, for the three models, extended by nearly $40 \mathrm{~km}$ in the final channel segment.
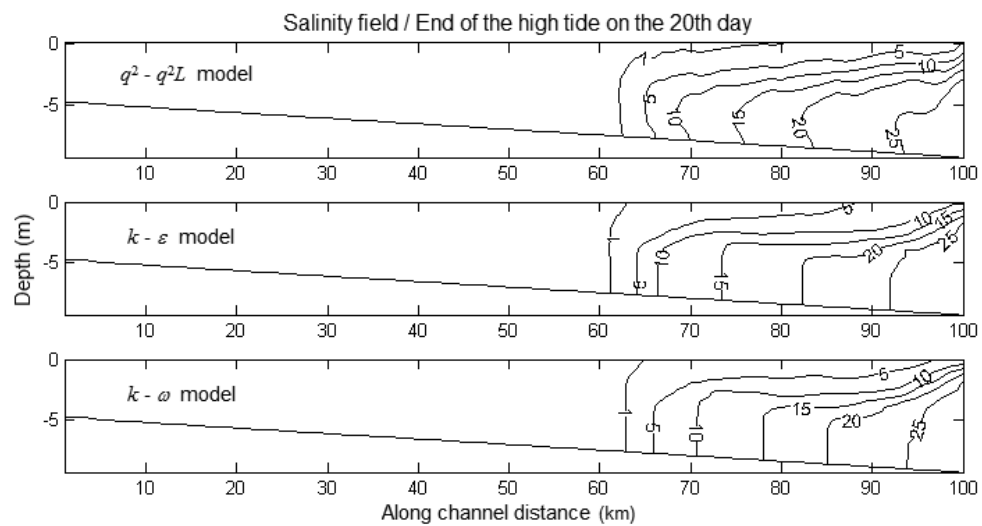

Figure 6 - Salinity field. Result of the model application at the end of the high tide after 40 tidal cycles. 

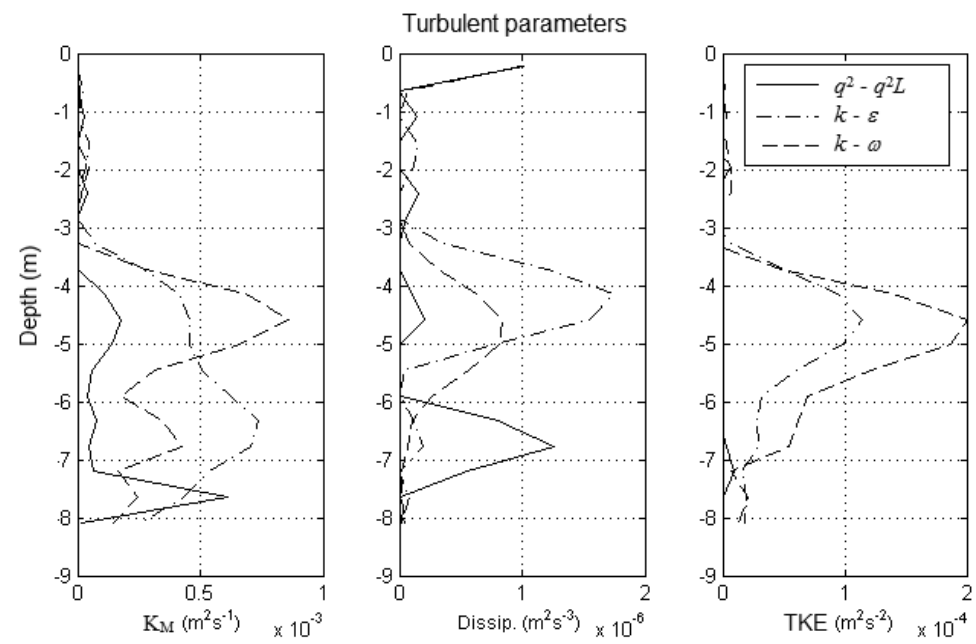

Figure 7 - Turbulent parameters in a central point situated at $70 \mathrm{~km}$ from the head, after 40 tidal cycles.

In this experiment, shear and buoyancy play an equally important role. The bottom saline layer flux and reflux against the fresh water surface generate strong shear in the interface producing the saline water penetration into the lighter surface layer. Therefore, the salinity structure that results from the numeric simulations with the three models led, in the mixing zone, to a vertically well stratified water column in the upper part, near the surface, and to a vertically well mixed bottom layer, as it was expected.

Although the three models present very similar results, some difference among them can be observed. The $q^{2}-q^{2} L$ model presents isohalines with some deflection in relation to the bottom and a greater vertical stratification in the upper part of the water column. The $k-\varepsilon$ and $k-\omega$ models, in turn, presented a well mixed water column in the bottom and less stratified in the surface, indicating that these models present a greater mixing capacity in relation to the $q^{2}-q^{2} L$ model in the entire water column

Figure 7 presents some characteristic turbulence parameters, that were determined in a transversal section at $\mathrm{km} 70$, for the three models. From left to right the turbulent viscosity $\left(K_{M}\right)$, the dissipation ratio $(\varepsilon)$ and the turbulent kinetic energy (TKE) are presented.

We can observe in the left panel that the $q^{2}-q^{2} L$ model presents viscosity coefficient values of the same order of magnitude of the other models, but clearly lower, explaining the smaller mixing capacity in the bottom region in relation to the $k-\varepsilon$ and $k-\omega$ models. In the upper part of the water column all parameter values are very low due to the strong vertical stratification in this region.

\section{CONCLUSIONS}

In this work two new turbulence closure schemes, known in literature as $k-\varepsilon$ and $k-\omega$, were implemented in the POM, which has already incorporated the Mellor \& Yamada (1982) $q^{2}-q^{2} L$ turbulence model type. To assess this implementation quality, i.e., to remove eventual codification problems, to assess the necessary restrictions to each incorporated model and eventual boundary condition problems, two test cases suggested in literature for this purpose were carried out: (i) deepening of the mixed layer and (ii) estuarine circulation. With the accomplishment of this work, we can conclude that:

1. All obtained results showed that the turbulence closure $k-\varepsilon$ and $k-\omega$ models implementation in the POM was adequate.

2. The different results among the models, for the same scenarios, are a consequence of the fact that each model gives a different relative importance to the different physical processes involved in the turbulent closure scheme, i.e., shear, buoyancy and dissipation. This importance results from the different coefficients assigned to each model for these processes, as Table 1 shows, and it directly affects Equation (17), from which the turbulence length scale is determined. For example, according to these coefficients, the $k-\varepsilon$ model tends to favor more the shear process than the others, and in this scenario this is probably making this model overestimate the mixed layer deepening in relation to the others. This fact, however, was not observed in Warner et al. (2005), whose simulations were carried out using the ROMS model, although in the 
present work the same coefficients employed by those authors have been used. This motivated the next conclusion.

3. A comparison among the results obtained in this work using the $k-\varepsilon$ and $k-\omega$ models with the results obtained by Warner et al. (2005), for the same scenarios and coefficients in Table 1, suggests that the results are also affected by the numeric structure (discretization criteria, numerical diffusion minimization schemes, and others) of the used circulation hydrodynamic model.

4. The modification proposed by Burchard \& Deleersnijder (2001), to increase the $c_{3}$ coefficient related to the fluctuability term, did not eliminated the oscillations, observed using the $q^{2}-q^{2} L$ model, in the ML deepening and did not reduced either the mixed layer depth. This impact was expected, as the increase in this term intensifies the turbulence damping.

5. In the scenario defined by the first experiment, the $k-$ $\varepsilon$ model presented a greater mixing capacity than the $q^{2}-q^{2} L$ model, and this last model presented a greater capacity than the $k-\omega$ model. In the second experiment scenario, the $k-\varepsilon$ and $k-\omega$ models showed a greater mixing capacity than the $q^{2}-q^{2} L$ model, in the bottom layer as well as in the surface layer of the MZ. Although the observed differences are small, they indicate that the performance of each model depends basically on the scenario where it is employed.

6. To use one or another turbulence closure model, in a real flow situation, it is necessary to assess which one of them most truthfully reproduces the behaviour of this flow.

\section{REFERENCES}

ALVES FNA. 2006. Estudo do transporte de óleo por um modelo lagrangeano de partículas na Bacia de Pelotas. Master dissertation on Physical, Chemical and Geological Oceanography. FURG. 158 pp.

BURCHARD H. 2002. Applied Turbulence Modelling in Marine Waters. Lecture Notes in Earth Sciences. Springer-Verlag, Germany. 215 pp.

BURCHARD H \& BOLDING K. 2001. Comparative Analysis of Four Second-Moment Turbulence Closure Models for the Oceanic Mixed Layer. Journal of Physical Oceanography, 31: 1943-1968.

BURCHARD H \& DELEERSNIJDER E. 2001. Stability of algebraic nonequilibrium second-order closure models. Ocean Modelling, 3: 33-50.

BURCHARD $H$ \& PETERSEN 0. 1999. Models of turbulence in the marine environment - A comparative study of two-equation turbulence models. Journal of Marine Systems, 21: 29-53.
BURCHARD $H$, CRAIG PD, GEMMRICH JR, VAN HAREN H, MATHIEU P-P, MEIER HEM, SMITH WAMN, PRANDKE H, RIPPETH TP, SKYLLINGSTAD ED, SMYTH WD, WELSH DJS \& WIJESEKERA HW. 2008. Observational and numerical modeling methods for quantifying coastal ocean turbulence and mixing. Progress in 0ceanography, 76(4): 399-442.

CUSHMAN-ROISIN B \& BECKERS JM. 2011. Introduction to Geophysical Fluid Dynamics - Physical and Numerical Aspects. Academic Press, 828 pp.

DAVIES AM, LUYTEN, PJ \& DELEERSNIJDER E. 1995. Turbulence Energy Models in Shallow Sea Oceanography. Quantitative Skill Assessment for Coastal Ocean Models, Coastal and Estuarine Studies, 47: $97-123$.

DESCHAMPS CJ. 2002. Modelos Algébricos e Diferenciais. In: Coleção Cadernos de Turbulência. Associação Brasileira de Ciências Mecânicas - ABCM. Rio de Janeiro. Vol. 1, Cap. 3, p. 101-155.

FONTOURA RODRIGUES JLA. 2003. Escoamentos Turbulentos Parietais. In: Coleção Cadernos de Turbulência. Associação Brasileira de Ciências Mecânicas - ABCM. Rio de Janeiro. Vol. 2, Cap. 3, p. 153-204.

GALPERIN B, KANTHA LH, HASSID S \& ROSATI A. 1988. A QuasiEquilibrium Turbulent Energy Model for Geophysical Flows. Journal of Atmospheric Sciences, 45: 55-62.

ILICAK M, ÖZGÖKMAN TM, PETERS H, BAUMERT H \& ISKANDARANI M. 2008. Performance of two-equation turbulence closures in threedimensional simulations of the Red Sea overflow. Ocean Modelling, 24: $122-139$.

KANTHA LH \& CLAYSON CA. 1994. An Improved Mixed Layer Model for Geophysical Applications. Journal of Geophysical Research, 99(C12): 25235-25266.

KATO H \& PHILLIPS OM. 1969. On the penetration of a turbulent layer into stratified fluid. Journal of Fluid Mechanics, 37(4): 643-655.

MELLOR GL 2004. A three-dimensional, primitive equation, numerical ocean model. Users guide for the Princeton Ocean Model. 56 p. Available on: <http://aos.princeton.edu/WWWPUBLIC/htdocs.pom/publications.htm.> Access on: May 05, 2011.

MELLOR GL \& BLUMBERG AF. 2004. Wave Breaking and Ocean Surface Layer Thermal Response. Journal of Physical Oceanography. Notes and Correspondence, 34: 693-698.

MELLOR GL \& YAMADA T. 1974. A Hierarchy of Turbulence Closure Models for Planetary Boundary Layers. Journal of Atmospheric Sciences, 31: 1791-1806.

MELLOR GL \& YAMADA T. 1982. Development of a Turbulence Closure Model for Geophysical Fluid Problems. Reviews of Geophysics and Space Physics, 20: 851-875. 
MIRANDA LB, CASTRO BM \& KJERFVE B. 2002. Princípios de Oceanografia Física de Estuários. Edusp, Editora da Universidade de São Paulo. 424 pp.

PETERS H \& BAUMERT H. 2007. Validating a turbulence closure against estuarine microstructure measurements. Ocean Modelling, 19: 183-203.

RODI W. 1987. Examples of Calculation Methods for Flow and Mixing in Stratified Fluids. Journal of Geophysical Research, 92(C5): 53035328.

RODI W. 1993. Turbulence Models and Their Application in Hydraulics. IAHR - International Association for Hydraulic Research, 3rd ed., 104 pp.

SOUZA JFA. 2011. Um Estudo dos Processos de Mistura em Correntes Costeiras Sob Diferentes Concepções de Fechamento Turbulento. Doctorate thesis on Physical, Chemical and Geological Oceanography. Instituto de Oceanografia. Universidade Federal do Rio Grande. 196 pp.

SOUZA JFA, OLIVEIRA LR, AZEVEDO JLL, SOARES ID \& MATA MM.
2011. Uma Revisão sobre a Turbulência e sua Modelagem. Revista Brasileira de Geofísica, 29(1): 21-41.

THORPE SA. 2005. The Turbulent Ocean. Cambridge University Press, $439 \mathrm{pp}$.

UMLAUF L \& BURCHARD H. 2003. A Generic Length-Scale Equation for Geophysical Turbulence Models. Journal of Marine Research, 61: 235-265.

UMLAUF L \& BURCHARD H. 2005. Second-order turbulence closure models for geophysical boundary layers. A review of recent work. Continental Shelf Research, 25: 795-827.

UMLAUF L, BURCHARD H \& HUTTER K. 2003. Extending the $k-\omega$ turbulence model towards oceanic applications. Ocean Modelling, 5: 195-218.

WARNER JC, SHERWOOD CR, ARANGO HG \& SIGNELL RP. 2005 Performance of a four turbulence closure models implemented using a generic length scale method. Ocean Modelling, 8: 81-113.

\section{NOTES ABOUT THE AUTHORS}

José Francisco Almeida de Souza. Undergraduated in Civil Engineering at FURG (1979), Master degree in Civil Engineering, focusing Hydric Resources and Sanitation, at UFRGS (1990) and Doctor degree in Physical, Chemical and Geological Oceanography at FURG (2011). Presently is a professor at Escola de Engenharia (EE) of FURG and the research area is the turbulence modeling with application in fluctuating plume formation using the Princeton Ocean Model - POM. The turbulent aspects of the costal and estuarine circulation are in his area of interest.

José Luiz Lima de Azevedo. Undergraduated in Chemical Engineering at FURG (1982), Master degree in Electrical Engineering at UFSC (1996) and Doctor degree in Physical, Chemical and Geological Oceanography at FURG (2009). Since 1984 is a professor at FURG, and the research area is the analytical and numeric modeling of the encounter of anticyclonic vortices with the continental border and the respective boundary current. The numeric modeling, using the Princeton Ocean Model POM and the Bleck \& Boudra model, and the study of climatological data originated from the profiling floats of the ARGO project are in his area of interest.

Leopoldo Rota de Oliveira. Undergraduated in Physics at UFPEL (1998), Master (2003) and Doctor (2008) degrees in Physical, Chemical and Geological Oceanography at FURG (2008). Worked as a Physics professor (4 years UFPEL/FURG). His scientific works emphasize Physical Oceanography, medium and large scale oceanic circulation, and the main subjects and regions are: spatial and temporal variability, conversions of energies associated to dynamic instabilities, reverse energy cascade and superficial heat flux of oceanic currents for the Southwest Atlantic and Austral Ocean.

Ivan Dias Soares. Undergraduated in Oceanology at FURG (1986), Master degree in Physical Oceanography at USP (1995) and Doctor degree in Meteorology and Physical Oceanography at Rosenstiel School of Marine and Atmospheric Science - University of Miami, Florida, USA (2003). Presently is an Adjunct Professor at FURG.

Maurício Magalhães Mata. Undergraduated in Oceanography (FURG, 1991) and Master degree in Remote Sensing (UFRGS, 1996). Doctor degree in 2001 in Physical Oceanography at Flinders University of South Australia, Adelaide, Australia. Permanent professor at Oceanographic Institute of FURG since 1992. Presently is the coordinator of the post-graduate course in Physical, Chemical and Geological Oceanography at FURG. The research area is the medium and large scale oceanic circulation, emphasizing west boundary currents and Antarctic Oceanography. Special interest in the interannual processes that control the formation and exportation of bottom waters around the Antarctic continent. 